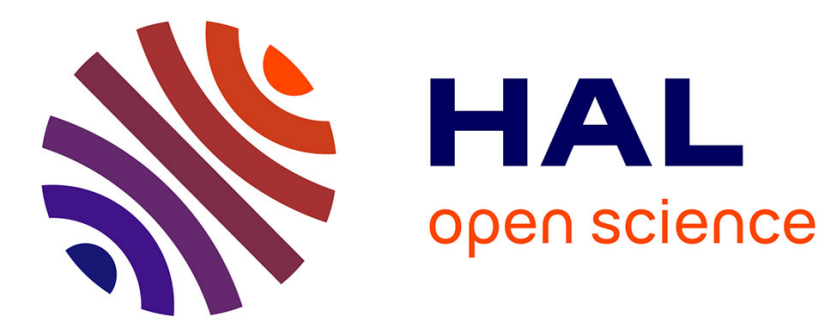

\title{
GaAsPN-based PIN solar cells MBE-grown on GaP substrates: toward the III-V/Si tandem solar cell
} Mickael da Silva, Samy Almosni, C. Cornet, Antoine Létoublon, Christophe Levallois, Pierre Râle, Laurent Lombez, Jean-François Guillemoles, Olivier Durand

\section{To cite this version:}

Mickael da Silva, Samy Almosni, C. Cornet, Antoine Létoublon, Christophe Levallois, et al.. GaAsPN-based PIN solar cells MBE-grown on GaP substrates: toward the III-V/Si tandem solar cell. SPIE Photonics West - OPTO 2015, Feb 2015, San Francisco, United States. pp.93580H, 10.1117/12.2081376 . hal-01166431

\section{HAL Id: hal-01166431 \\ https://hal.science/hal-01166431}

Submitted on 22 Jun 2015

HAL is a multi-disciplinary open access archive for the deposit and dissemination of scientific research documents, whether they are published or not. The documents may come from teaching and research institutions in France or abroad, or from public or private research centers.
L'archive ouverte pluridisciplinaire HAL, est destinée au dépôt et à la diffusion de documents scientifiques de niveau recherche, publiés ou non, émanant des établissements d'enseignement et de recherche français ou étrangers, des laboratoires publics ou privés. 


\title{
GaAsPN-based PIN solar cells MBE-grown on GaP substrates: toward the III-V/Si tandem solar cell.
}

\author{
M. Da Silva ${ }^{1}$, S. Almosni ${ }^{1}$, C. Cornet ${ }^{1}$, A. Létoublon $^{1}$, C. Levallois ${ }^{1}$, P. Rale ${ }^{2}$, L. Lombez ${ }^{2}$, J.-F. \\ Guillemoles $^{2}$, O. Durand ${ }^{\mathrm{a}, 1}$ \\ ${ }^{1}$ Université Européenne de Bretagne, France \\ INSA, FOTON-OHM, UMR 6082, F-35708 Rennes, France \\ ${ }^{2}$ Institut de Recherche et Développement sur l'Energie Photovoltä̈que (IRDEP), UMR 7174 - \\ CNRS-EDF-ENSCP, EDF R\&D, 6 quai Watier, 78401 Chatou Cedex, France \\ a e-mail: olivier.durand@insa-rennes.fr
}

\begin{abstract}
GaAsPN semiconductors are promising material for the elaboration of high efficiencies tandem solar cells on silicon substrates. GaAsPN diluted nitride alloy is studied as the top junction material due to its perfect lattice matching with the Si substrate and its ideal bandgap energy allowing a perfect current matching with the Si bottom cell. We review our recent progress in materials development of the GaAsPN alloy and our recent studies of some of the different building blocks toward the elaboration of a PIN solar cell. A lattice matched (with a $\mathrm{GaP}(001)$ substrate, as a first step toward the elaboration on a Si substrate) $1 \mu \mathrm{m}$-thick GaAsPN alloy has been grown by MBE. After a post-growth annealing step, this alloy displays a strong absorption around 1.8-1.9 eV, and efficient photoluminescence at room temperature suitable for the elaboration of the targeted solar cell top junction. Early stage GaAsPN PIN solar cells prototypes have been grown on $\mathrm{GaP}(001)$ substrates, with 2 different absorber thicknesses $(1 \mu \mathrm{m}$ and $0.3 \mu \mathrm{m})$. The external quantum efficiencies and the I-V curves show that carriers have been extracted from the GaAsPN alloy absorbers, with an open-circuit voltage of $1.18 \mathrm{~V}$, while displaying low short circuit currents meaning that the GaAsPN structural properties needs a further optimization. A better carrier extraction has been observed with the absorber displaying the smallest thickness, which is coherent with a low carriers diffusion length in our GaAsPN compound. Considering all the pathways for improvement, the efficiency obtained under AM1.5G is however promising.
\end{abstract}

Keywords: III-V semiconductors; dilute nitride ; molecular beam epitaxy ; multijunction solar cells ; silicon

\section{INTRODUCTION}

Up to now, the most efficient solar energy conversion systems are monocrystalline multijunction solar cells (MJSC) based on III-V semiconductor materials operating under concentrated sunlight. SOITEC and Fraunhofer Institute have pushed solar cell record to $44.7 \%$ for terrestrial applications, with a wafer bonded four-junction $\mathrm{GaInP} / \mathrm{GaAs} / / \mathrm{GaInAsP} / \mathrm{GaInAs}$ solar cell under concentration of 297 suns ${ }^{1}$, and announced very recently a $46 \%$ efficiency under concentration of 508 suns, in the SOITEC website. Moreover, a III-V triple junction coherently grown (lattice-matched) onto GaAs substrate has been performed by Solar Junction. This solar cell has shown a $44.4 \%$ efficiency under 942 suns (AM1.5D spectra) ${ }^{2}$ due to the use of an $1 \mathrm{eV}$ GaInAsNSb diluted-nitride junction that allow a good current matching with the GaAs and GaInP top junction. The main downside of this approach is the substantial costs of III-V substrates compared to silicon

Physics, Simulation, and Photonic Engineering of Photovoltaic Devices IV, edited by Alexandre Freundlich, Jean-François Guillemoles, Masakazu Sugiyama, Proc. of SPIE Vol. 9358, 93580H · (c) 2015 SPIE CCC code: $0277-786 X / 15 / \$ 18 \cdot$ doi: $10.1117 / 12.2081376$ 
material which profits from its abundance, mature technology and the wide microelectronics market. Obviously, the integration of III-V junctions on silicon substrate would allow to reach the III-V high efficiencies while benefitting from the advantageous Si substrates cost. This approach would enable to realize a strategic reduction of the solar cells final cost up to $0.25-0.5 € / \mathrm{Wp}$.

A tandem cell with a $1.7 \mathrm{eV}$ III-V top junction on a $1.1 \mathrm{eV}$ monocrystalline $\mathrm{Si}$ bottom junction was theoretically studied by Geisz and Friedman, predicting efficiencies higher than $37 \%$ under AM $1.5 \mathrm{G}^{3,4,5,6}$. Still, structural defects such as dislocations would dramatically reduce the performance of such a structure by trapping the charge carriers. It is thus necessary to perform a lattice matched growth onto silicon. Our work consists of the development of a lattice matched III-V/c-Si tandem cell. We report here our results on the growth and the technological processing of the III-V top solar subcell preliminary grown on $\mathrm{GaP}(001)$. First, we describe the growth and the technologic process of this top III-V subcell. Then, we report our recent results about this III-V cell.

\section{EXPERIMENTAL DETAILS ON THE SOLAR CELL FABRICATION}

In order to develop low cost and high efficiency tandem solar cells on c-Si substrates, our group have oriented its research toward a lattice-matched GaAsPN based top cell grown on $\mathrm{GaP}(001)$, as a first stage towards the tandem cell development itself. Indeed, GaP is the III-V compound with the closest lattice parameter to $\mathrm{Si}$, with a lattice mismatch around $0.4 \%$, but its wide bandgap $(2.2 \mathrm{eV})$ makes it transparent for most of the solar spectrum. Moreover, GaP has an indirect band gap, which leads to low performances when used as an absorber. The introduction of small amount of As (typically 10\%) and $\mathrm{N}$ (typically 2\%) in GaP, leads to a pseudo-direct band gap material $(\mathrm{GaAsPN})$, while maintaining a perfect lattice matching with $\operatorname{GaP}(001)^{7}$. Moreover, the incorporation of a low amount of $\mathrm{N}$ enables to lower the bandgap towards the theoretical ideal value of $1.7 \mathrm{eV}$, thanks to a large bowing effect, property leading to a huge electronic bandgap variation with respect to a small nitrogen incorporation ${ }^{8,9,10}$. We have designed this top cell as a PIN diode - composed of an unintentionally doped GaAsPN absorber under a p-doped GaP layer - grown by molecular beam epitaxy (MBE) on a n-doped GaP substrate. The $\mathrm{p}$ and n-type doping are obtained during the growth thanks to beryllium and silicon cells respectively. We also report our results about ohmic contacts deposition on both $\mathrm{p}$ and n-type GaP substrates.

\subsection{Growth and post growth treatment.}

The III-V top cell is grown in a RIBER MBE chamber on a GaP(001) substrate. The group III elements, such as $\mathrm{Ga}$, are emitted by conventional Knudsen effusion cells from pure metal solid sources. The V elements, like $\mathrm{P}$ and As, are supplied by valved-cracker cells by heating solid sources. The basis pressure in the chamber is about $10^{-11}$ Torr while the growth pressure attains $10^{-7}-10^{-5}$ Torr. To grow the dilute nitride compound, the atomic $\mathrm{N}$ is produced by a valved Addon RF plasma cell, designed to avoid any ion irradiation of the sample during the growth, ${ }^{11}$ is used.

Based on the work of Harris et al. (2007) on the GaInAsN dilute-nitride compounds, a growth at low temperature $\left(480^{\circ} \mathrm{C}\right)$ has been chosen in order to minimize the point defects density and the phase separation known to occur in non-optimized dilute-nitride alloys growth ${ }^{12,13}$. It has also been found out that lowering the growth rate raises the nitrogen incorporation ${ }^{12}$. This provides a major asset for the controllability and the reproducibility of these dilute nitride compounds.

In dilute-nitride materials, post-growth treatments, such as annealing, is highly required to obtain the optimal optical properties for the targeted applications ${ }^{14}$. In particular, it has been shown that an annealing step after the growth reduces the alloy fluctuations and suppresses some of the remaining point defects in the dilute nitride compounds ${ }^{15}$ Such a process drastically improves the optical properties of the absorber ${ }^{12,16}$. Therefore, a first stage post growth annealing study (not shown here), has been performed. In the following, 
the structures have been annealed at $800^{\circ} \mathrm{C}$ for $5 \mathrm{~min}$ which has been found to dramatically improve the optical properties of the diluted nitride compounds.

\subsection{GaP doping}

The targeted structure is a PIN GaP/GaAsPN/GaP junction grown onto a GaP substrate. Therefore, the doping of $\mathrm{GaP}$ has been studied. $\mathrm{P}$ and $\mathrm{n}$ dopings of $\mathrm{GaP}$ are respectively obtained using solid $\mathrm{Be}$ and $\mathrm{Si}$ sources sublimated in Knudsen cells in the MBE chamber. C-V measurements performed on doped GaP layers grown on $\mathrm{GaP}$ substrates have been performed and allowed to draw the Arrhenius plots of each doping cell as represented in figures 1 and 2. Results on InP samples are shown for comparison.

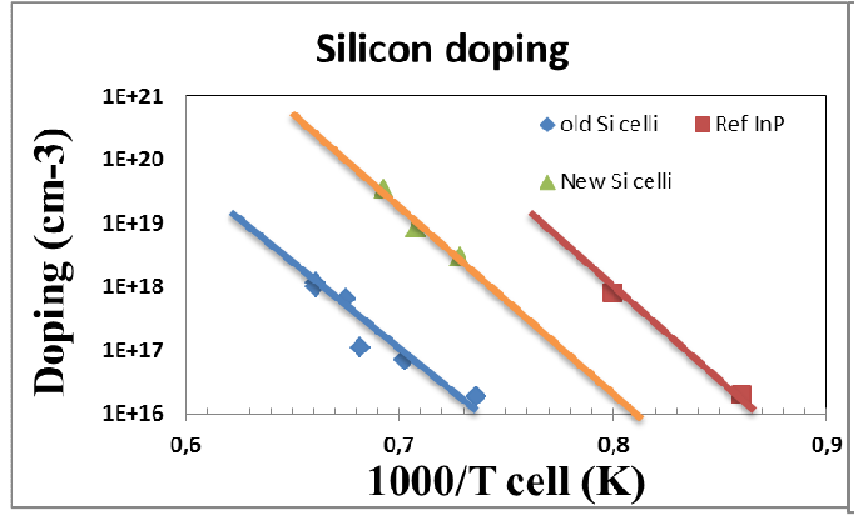

Fig. 1: Evolution of the n-type doping level for GaP and InP growths as a function of the reverse of the dopant cell temperature.

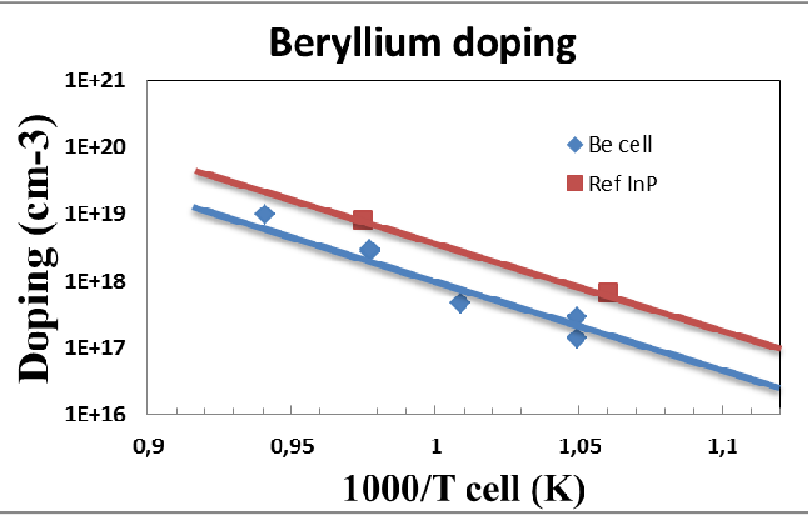

Fig. 2: Evolution of the p-type doping level for GaP and InP growths as a function of the reverse of the dopant cell temperature.

One can notice that the doping species modify the slope of the Arrhenius plot while the nature of the grown material does not have any influence. On figure 1, a former Si cell, with a conical geometry, is compared to a recently installed one, with a rounded back (whose purpose was the obtaining of a high doping level). As expected, this new cell allows higher doping levels than the former one, which enables us to achieve high doping levels - higher than $10^{19} \mathrm{~cm}^{-3}$ - for both $\mathrm{p}$ and $\mathrm{n}$ doping. These values are suitable for the growth of operating PIN solar cells and particularly for the development of an optimal tunnel junction (TJ) ${ }^{17}$. Indeed, both the top and bottom subcells of the tandem GaAsPN/Si double-junction solar cell will be electrically connected with a TJ.

\subsection{Ohmic contacts on GaP}

The elaboration of low resistance ohmic contacts is a key issue for an efficient collection of the photogenerated carriers. Contacts with a too high resistance would result in additional effects on the total current in the device, making the cell efficiency drop dramatically. The requirements for ideal ohmic contacts are linear and symmetrical I-V characteristic with a reliable and reproducible behavior. An optimized annealing step is necessary to ensure the mechanical stability of the metallic alloys. For n-type GaP substrate, we have referred to the work of Peternai et al. (2003) and have chosen to use a $\mathrm{Ni} / \mathrm{Au} / \mathrm{Ge}$ alloy ${ }^{18}$, annealed at $530^{\circ} \mathrm{C}$. This structure has shown a symmetrical ohmic contact characteristic with a good reproducibility and mechanical stability. In addition, we have obtained a low contact resistivity of $10^{-5} \Omega . \mathrm{cm}^{2}$ on a n-type GaP substrate $\left(\mathrm{n} \sim 10^{18} \mathrm{~cm}^{-3}\right)$. Regarding the p-doped $\mathrm{GaP}$, the use of a $\mathrm{Pd} / \mathrm{Au} / \mathrm{Zn}$ alloy has been reported to be a good choice ${ }^{19,20}$. After an annealing of $550^{\circ} \mathrm{C}$, we have been able to notice again an adequate ohmic behavior for this contact, with a low resistivity of $10^{-5} \Omega \cdot \mathrm{cm}^{2}$ on a p-type $\left(\mathrm{p} \sim 10^{18} \mathrm{~cm}^{-3}\right) \mathrm{GaP}$ substrate. 


\subsection{PIN solar cells development}

From a substrate...

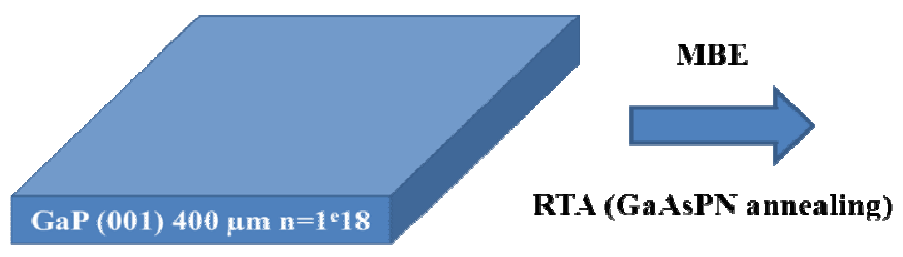

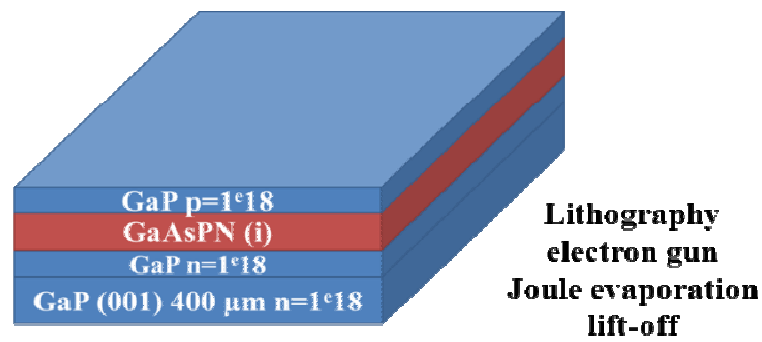
lift-off
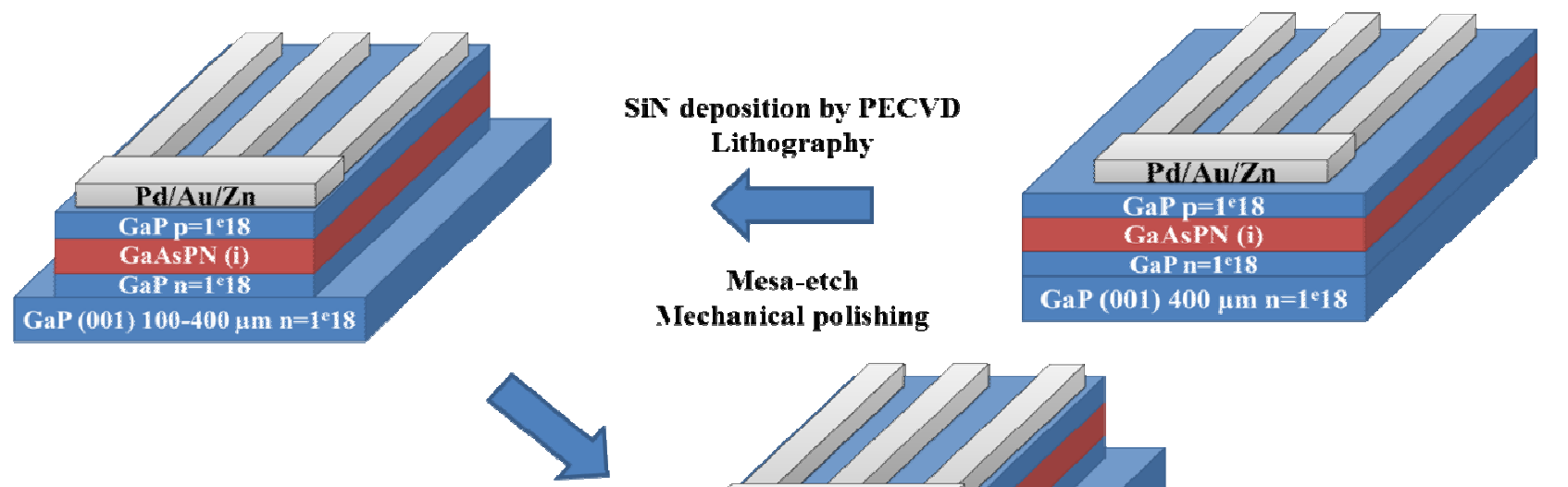

Electron gun $\mathrm{SiF}_{6}$ plasma (SiN removing)

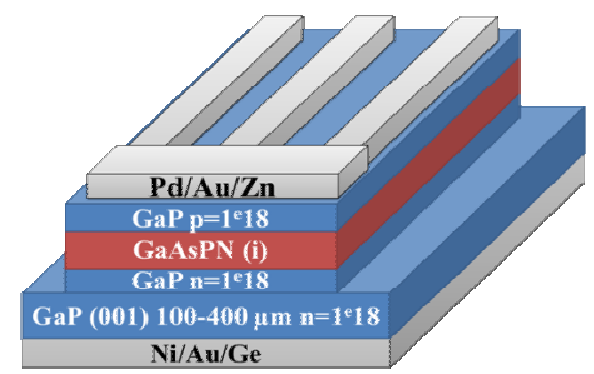

... to a solar cell

Fig. 3: PIN/GaP solar cells development flowchart.

In order to develop the top junction, GaP/GaAsPN PIN diodes have been grown on a n-type $\mathrm{GaP}(001)$ substrate. The structures consists of a p-doped (Be doped, $1.10^{18} \mathrm{~cm}^{-3}$ ) $\mathrm{GaP}$ window layer grown on a GaAsPN absorber, itself grown on a n-doped ( $\mathrm{Si}$ doped, $1.10^{18} \mathrm{~cm}^{-3}$ ) GaP bottom layer. The ohmic contacts on the front and back surfaces have been described previously. The front contact consists of a $5^{*} 5 \mathrm{~mm}^{2}$ grid with $10 \mu \mathrm{m}$ large fingers each spaced by $300 \mu \mathrm{m}$. The structure has been annealed at $800^{\circ} \mathrm{C}$ for 5 min in order to improve the optical properties of the diluted nitride compound. A front-fingered contact is deposited through a liftoff procedure, employing photolithography, after an oxide removal from the surface, done in a $5 \% \mathrm{HF}$ solution. The fingers, which size is $2.5 \mathrm{~mm} * 5 \mu \mathrm{m}$, are spaced from each other of $300 \mu \mathrm{m}$ (fig.3). The busbar size is $2.5 \mathrm{~mm} * 0.5 \mathrm{~mm}$. the $\mathrm{Pd} / \mathrm{Au} / \mathrm{Zn}$-based front contact is then deposited. All the photolithography steps have been performed in soft contact allowing line space resolution of $5 \mu \mathrm{m}$. After the lift-off process, the front sample surface is protected using photoresist and the substrate is thinned. Indeed, substrate thinning, using mechanical polishing, from $400 \mu \mathrm{m}$ to $200 \mu \mathrm{m}$ is important to improve the solar cell efficiency. We have observed that solar cells with a thinned substrate present an increase of the open-circuit voltage $\left(\mathrm{V}_{\text {oc }}\right)$, short circuit current $\left(\mathrm{J}_{\mathrm{sc}}\right)$ and fill factor (FF), leading to a significant improvement of their overall yields. This behavior has been attributed to the presence of detrimental impurities inside the GaP substrate, such as isoelectronic nearest-neighbor $\mathrm{Zn}-\mathrm{O}$ pair known to act as recombination centers ${ }^{21,22}$.

After the mechanical polishing, a SiN layer is deposited by plasma enhanced chemical vapor deposition (PECVD) at $300^{\circ} \mathrm{C}$ and a second photolithography step is done. Then, the SiN layer is etched by a reactive 
ion etching (RIE) process using SF6 gas. This dry etching step is then followed by a chemical etching to create $3 \mathrm{~mm} \times 2.5 \mathrm{~mm}$ mesas in order to ensure an electrical insulation between the front side and the back side of the solar cell. A hard SiN dielectric mask is used to protect the contact zone and the active area. After the dry etching, the SiN layer and remaining photoresist are removed. The sample is then dipped 30s in a 5\% $\mathrm{HF}$ chemical solution, dried and the Ni/Au/Ge contact is deposed using an electron gun on the back side of the sample. Finally a last annealing step is performed at $540^{\circ} \mathrm{C} 3 \mathrm{~min}$ to alloy both contacts at the same time.

\section{EARLY STAGE RESULTS ON PIN DIODES GROWN ON GAP SUBSTRATE}

We introduce here our early-stage results on PIN GaAsPN based solar cells development. The performances of each diode are discussed, as well as some routes for possible improvements. The performances evaluation is based on external quantum efficiency (EQE) measurements under AM1.5G. Quantum efficiency refers to the ratio between the number of incident photons and the number of collected charge carriers from the device. EQE does not take into account the amount of photons reflected or transmitted by the structure, thus this experiment also includes the power losses due to absorption limitations (lack of anti-reflection coating for instance). I-V curves showing the $\mathrm{J}_{\mathrm{sc}}$, the $\mathrm{V}_{\mathrm{oc}}$, the FF and the efficiency of every cell have also been plotted.

\subsection{Study of a $1 \mu$ m-thick absorber grown on a $\mathrm{GaP}(001)$ substrate}

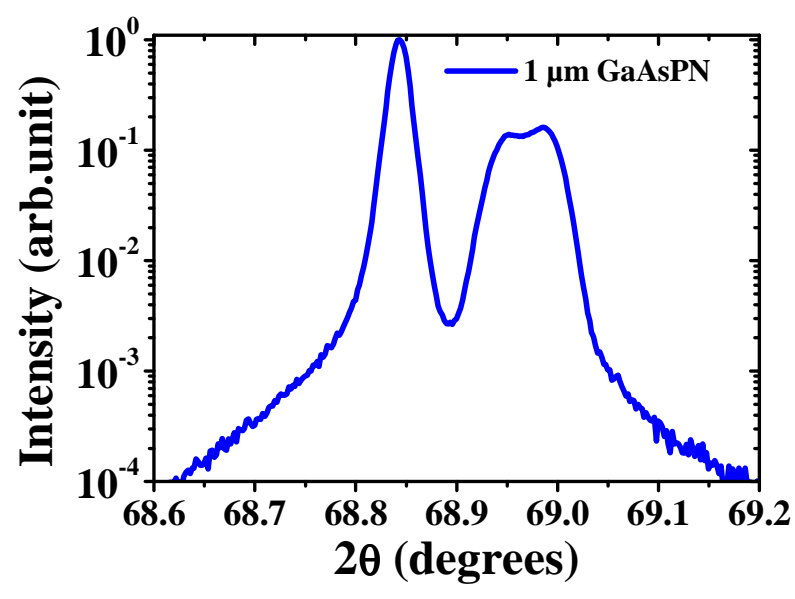

Fig. 4: XRD diagram performed around the (004) GaP reflection of a $1 \mu \mathrm{m}$ thick GaAsPN layer grown quasi lattice matched with the GaP substrate.

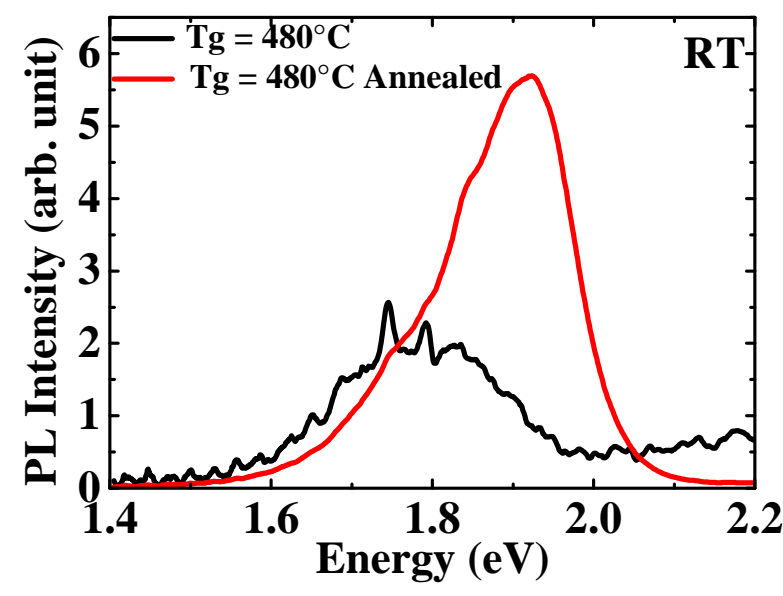

Fig. 5: RT PL spectra of a $1 \mu \mathrm{m}$ thick GaAsPN layer grown on a $\mathrm{GaP}$ substrate, before annealing (black line) and annealed at $800^{\circ} \mathrm{C}$ during 5 min (red line).

In a first step, a $1 \mu$ m-thick absorber has been used to ensure an optimal absorption of the incident light inside the absorber. This thickness has been theoretically determined after a first simulation of the PIN structure using SILVACO software. The $1 \mu \mathrm{m}$-thick GaAsPN layer, with an estimated composition of $\mathrm{GaAs}_{0.10} \mathrm{P}_{0.88} \mathrm{~N}_{0.02}$ (from X-ray diffraction experiments on a GaPN compound grown in the same conditions and taking into account the As incorporation), displays no structural relaxation due to its low mismatch $(0.07 \%)$ with the GaP substrate, as measured through X-ray diffraction. However, a very small peak splitting has been observed (fig.4). This effect could be related to a small composition fluctuation, as already observed in the GaInAsN material and which has been attributed to a "phase separation" ${ }^{12}$. Moreover, an optical gap of around $1.8 \mathrm{eV}$ has been measured through Room Temperature Photoluminescence (PL) measurement (fig.5). 
One can observed a low energy tail in the PL spectra, which is typical of the dilute-nitrides materials and usually attributed to local density of states due to alloy fluctuations effects from nitrogen clusters ${ }^{14,23}$.

\subsection{PIN diode with a $1 \mu \mathrm{m}$ thick GaAsPN absorber}

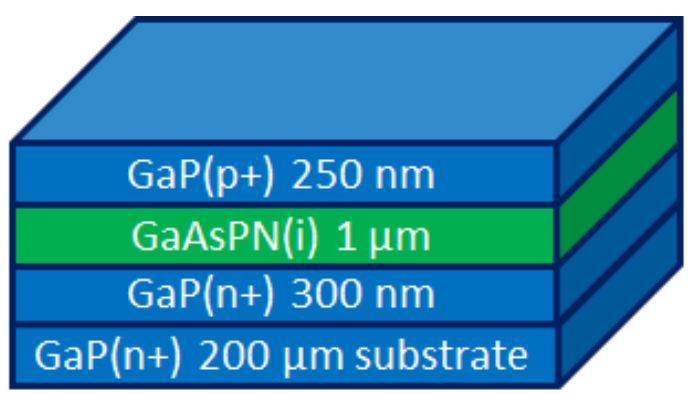

Fig. 6: Structure of the GaP/GaAsPN/GaP PIN diode (sample 1) with a $1 \mu$ m thick absorber.

Our first design for the development of a GaP/GaAsPN/GaP PIN diode is described in figure 6. This sample is labelled sample 1 in the following. The EQE and I-V curves are shown in figures 8 . The EQE shows an encouraging response at low energy, around $30 \%$, and a weak response at higher energy. The last effect has been attributed to the top 250-nm thick GaP highly doped layer absorption. I-V characteristics under AM1.5G illumination condition has been measured (fig 8). While the measured open-circuit voltage $\mathrm{V}_{\text {oc }}$ is $1.18 \mathrm{~V}$, the FF of $50 \%$ and the efficiency of $1.6 \%$ are limited by a small short-circuit current $\mathrm{J}_{\mathrm{sc}}$ of $2.8 \mathrm{~mA} / \mathrm{cm}^{2}$, far from the state-of-the art ${ }^{4}$. The I-V curve behavior seems to indicate a low carriers extraction from the solar cell. One can assume that the absorber thickness is too large compared to the diffusion length of the carriers in this material ${ }^{24}$ whose structural properties has to be optimised. Measurement of the carriers diffusion length in our GaAsPN compounds will be done in a forthcoming study. Therefore, we aimed to reduce this thickness to improve the solar cell properties.

\subsection{PIN diode with a $0.3 \mu \mathrm{m}$ thick GaAsPN absorber}

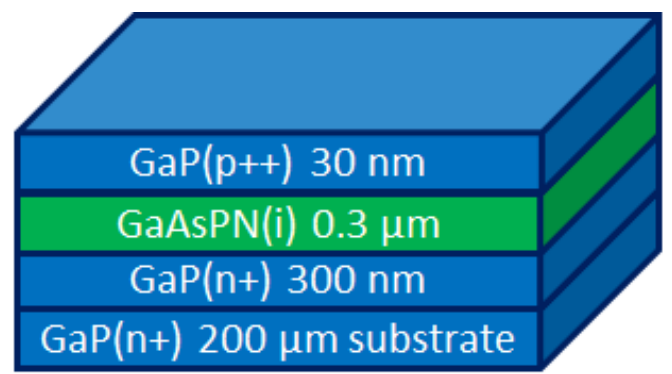

Fig. 7: Structure of the GaP/GaAsPN/GaP PIN diode (sample 2) with a $300 \mathrm{~nm}$ thick absorber.

As depicted in figure 7, both the GaAsPN absorber and the GaP (p+) top layer have been thinned in order to, first, obtain a better carrier collection, while lowering the light absorption. Figure 8 shows the EQE results of each reported sample. Compared to the previous sample, the response at low energy of sample 2 is close, 
while lower, to the one obtained with sample 1, which shows that the carrier collection has been improved, taking into account the smaller thickness. The larger response at higher energy has been attributed to the lower light absorption in the top GaP highly doped layer, much thinner that in sample 1.This is in agreement with our assumption of a low carriers collection in our GaAsPN absorber. Concerning the I-V curve under AM1.5G illumination conditions, this cell has displayed a $\mathbf{J}_{\mathrm{sc}}$ of $3.8 \mathrm{~mA} / \mathrm{cm}^{2}$, larger than in sample 1 . While $\mathrm{V}_{\mathrm{oc}}$ is slightly lower at $0.88 \mathrm{~V}$, which has not been understood so far, a remarkable fill factor of $71 \%$ has been measured. Finally, an encouraging $2.3 \%$ efficiency has been obtained ${ }^{25}$.

\subsection{Influence of the growth rate}

Sample 3 has exactly the same design than sample 2. The only change consisted in a lower growth rate. Indeed, as mentioned previously, it has been observed that the lower the growth rate, the higher is the $\mathrm{N}$ content ${ }^{12}$, so that we expect to obtain a higher nitrogen incorporation in the GaAsPN compound and, therefore a lower GaAsPN bandgap, much closer to the expected $1.7 \mathrm{eV}$. Indeed, the EQE results in a lower cut-off at low energy, as expected, which is accompanied by a higher $J_{\mathrm{sc}}\left(4.1 \mathrm{~mA} / \mathrm{cm}^{2}\right)$ in the $\mathrm{I}-\mathrm{V}$ under illumination. $\mathrm{V}_{\mathrm{oc}}$ is unchanged but a resistive effect shown by the shape of the I-V curve at low voltage results in lower fill factor $(49 \%)$ and efficiency $(1.75 \%)$. Still, this sample remains interesting since the electric current in the final tandem cell structure will be limited by the weakest current of the subcells taken alone. In other words, it might be appealing to slightly sacrifice the cell efficiency so as to maintain the current matching in the whole device. Moreover, these new growth parameters imply a forthcoming optimisation of the overall growth, as well as post-growth annealing, along with an experimental study of different absorber thicknesses between $0.3 \mu \mathrm{m}$ and $1 \mu \mathrm{m}$.
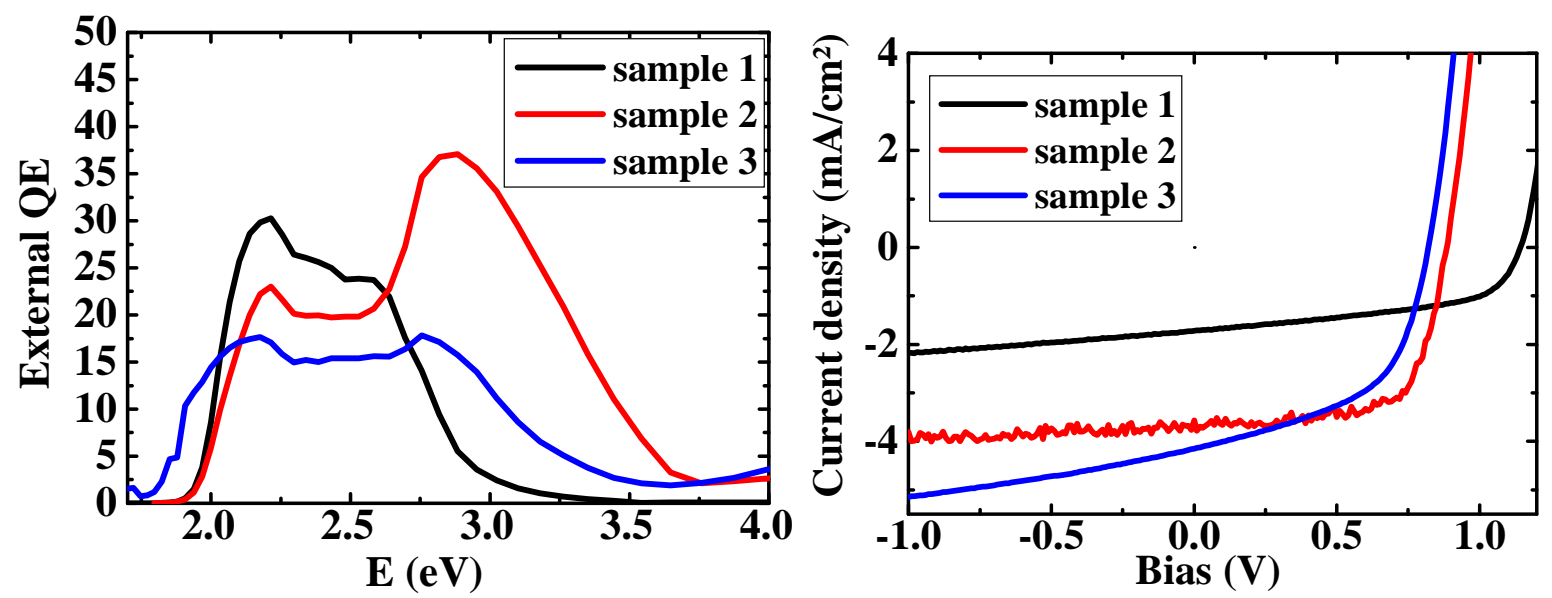

Fig. 8: EQE versus energy (left) and I-V curves under illumination (AM1.5G) (right) for the three GaP/GaAsPN/GaP PIN diodes.

\subsection{Conclusion}

Those early stage results have to be compared to the state-of-the-art device developed by Geisz et al. in 2002. Their GaP/GaAsPN(600nm)/GaP PIN diode reached the efficiency of $3.8 \%$ with a $5.8 \mathrm{~mA} / \mathrm{cm}^{2} \mathrm{~J}_{\mathrm{sc}}$ a $1.1 \mathrm{~V} \mathrm{~V} \mathrm{~V}_{\mathrm{oc}}$ $(\mathrm{Eg}=1.88 \mathrm{eV})$ and a FF of $60 \%{ }^{4}$. Our approach is promising considering all the possible routes for improvement. Mainly, sample 2 with a $300 \mathrm{~nm}$ thick GaAsPN absorber displayed a promising $\eta=2.3 \%$, with a FF of $70 \%$. Its main shortcoming comes from its weak current collection which shows the necessity to optimize the cell architecture and the GaAsPN structural properties. 


\section{CONCLUSION}

We have reported first-stage-stage results on GaP/GaAsPN/GaP PIN solar cells grown by MBE on GaP(001) substrates, toward the development of a III-V/Si tandem solar cell. Moreover, we have achieved the development of high doping levels of the GaP layers, suitable for the development of an efficient TJ, and suitable quality ohmic contacts. Our best efficiency result $(2.3 \%)$ has been obtained with a $300 \mathrm{~nm}$-thick GaAsPN absorber, while $1 \mu \mathrm{m}$ is required for an optimal light absorption. Indeed, GaAsPN is an emerging material not fully optimized so far. However, an EQE around $30 \%$ and FF of $70 \%$ have been demonstrated, and $\mathrm{a} \mathrm{V}_{\mathrm{OC}}$ of $1.18 \mathrm{~V}$ has been reached. Moreover, much progress has been realized in the comprehension of the influence of growth and annealing parameters and the control of the GaAsPN composition. Nevertheless, there is yet a room for improvement of the structural characteristics of the material, and, therefore on its optical properties. Moreover, we obtained these results despite the lack of any anti-reflective layers and passivation coating. In addition to further optimizations, our forthcoming work will include the study of these coatings and the development of a high performance TJ for the electrical connection between both subcells ${ }^{17}$. Finally, the III-V top cell will be grown on the Si bottom one to complete the tandem cell. In this regard, our group have also developed a strategy to grow GaP defect-free layers on silicon, avoiding most of the local chemistry mismatch at the $\mathrm{GaP} / \mathrm{Si}$ interface such as anti-phase domains and microtwins which are typical of epitaxies of polar materials on non-polar ones ${ }^{26-31}$.

Acknowledgments: This work was supported by the French ANR, project MENHIRS (grant $\mathrm{N}^{\circ}$ ANR-2011-PRGE-007-0).

\section{REFERENCES}

[1] Dimroth, F., Grave, M., Beutel, P., Fiedeler, U., Karcher, C., Tibbits, T. N. D., Oliva, E., Siefer, G., Schachtner, M., et al., "Wafer bonded four-junction GaInP/GaAs//GaInAsP/GaInAs concentrator solar cells with 44.7\% efficiency," Prog. Photovolt. Res. Appl. 22(3), 277-282 (2014).

[2] Derkacs, D., Jones-Albertus, R., Suarez, F.., Fidaner, O., "Lattice-matched multijunction solar cells employing a 1 eV GaInNAsSb bottom cell," J. Photonics Energy 2(1), 021805-1 (2012).

[3] Kurtz, S. R., Faine, P.., Olson, J. M., "Modeling of two-junction, series-connected tandem solar cells using top-cell thickness as an adjustable parameter,” J. Appl. Phys. 68(4), 1890-1895 (1990).

[4] Geisz, J. F., Olson, J. M., Friedman, D. J., Jones, K. M., Reedy, R. C.., Romero, M. J., "Latticematched GaNPAs-on-silicon tandem solar cells," Conf. Rec. Thirty-First IEEE Photovolt. Spec. Conf. 2005, 695-698 (2005).

[5] Geisz, J. F.., Friedman, D. J., "III-N-V semiconductors for solar photovoltaic applications," Semicond. Sci. Technol. 17(8), 769 (2002).

[6] Geisz, J. F., Friedman, D. J.., Kurtz, S., "GaNPAs solar cells lattice-matched to GaP," Conf. Rec. Twenty-Ninth IEEE Photovolt. Spec. Conf. 2002, 864-867 (2002).

[7] Chamings, J., Adams, A. R., Sweeney, S. J., Kunert, B., Volz, K.., Stolz, W., “Temperature dependence and physical properties of $\mathrm{Ga}(\mathrm{NAsP}) / \mathrm{GaP}$ semiconductor lasers," Appl. Phys. Lett. 93(10), 101108 (2008).

[8] Shan, W., Walukiewicz, W., Yu, K. M., Wu, J., Iii, J. W. A., Haller, E. E., Xin, H. P.., Tu, C. W., "Nature of the fundamental band gap in GaNxP1-x alloys," Appl. Phys. Lett. 76(22), 3251-3253 (2000). 
[9] Robert, C., Bondi, A., Thanh, T. N., Even, J., Cornet, C., Durand, O., Burin, J. P., Jancu, J. M., Guo, W., et al., "Room temperature operation of $\mathrm{GaAsP}(\mathrm{N}) / \mathrm{GaP}(\mathrm{N})$ quantum well based light-emitting diodes: Effect of the incorporation of nitrogen," Appl. Phys. Lett. 98(25), 251110 (2011).

[10] Xin, H. P., Tu, C. W., Zhang, Y.., Mascarenhas, A., "Effects of nitrogen on the band structure of GaNxP1-x alloys," Appl. Phys. Lett. 76(10), 1267-1269 (2000).

[11] Kuyyalil, J., Nguyen Thanh, T., Quinci, T., Almosni, S., Létoublon, A., Rohel, T., Bertru, N., Le Corre, A., Durand, O., et al., "Nitrogen-phosphorus competition in the molecular beam epitaxy of GaPN," J. Cryst. Growth 377, 17-21 (2013).

[12] Harris, J. S., Kudrawiec, R., Yuen, H. B., Bank, S. R., Bae, H. P., Wistey, M. A., Jackrel, D., Pickett, E. R., Sarmiento, T., et al., "Development of GaInNAsSb alloys: Growth, band structure, optical properties and applications," Phys. Status Solidi B 244(8), 2707-2729 (2007).

[13] Aho, A., Polojärvi, V., Korpijärvi, V.-M., Salmi, J., Tukiainen, A., Laukkanen, P.., Guina, M., "Composition dependent growth dynamics in molecular beam epitaxy of GaInNAs solar cells," Sol. Energy Mater. Sol. Cells 124, 150-158 (2014).

[14] Utsumi, A., Yonezu, H., Furukawa, Y., Momose, K.., Kuroki, K., "Increase in luminescence efficiency of GaPN layers by thermal annealing," Phys. Status Solidi C(7), 2741-2744 (2003).

[15] Jussila, H., Yu, K. M., Kujala, J., Tuomisto, F., Nagarajan, S., Lemettinen, J., Huhtio, T., Tuomi, T. O., Lipsanen, H., et al., "Substitutionality of nitrogen atoms and formation of nitrogen complexes and point defects in GaPN alloys," J. Phys. Appl. Phys. 47(7), 075106 (2014).

[16] Aho, A., Tukiainen, A., Polojärvi, V., Salmi, J.., Guina, M., "High current generation in dilute nitride solar cells grown by molecular beam epitaxy," Proc. SPIE 8620, Physics, Simulation, and Photonic Engineering of Photovoltaic Devices II, 86201I - 86201I - 6 (2013)

[17] Rolland, A., Pedesseau, L., Even, J., Almosni, S., Robert, C., Cornet, C., Jancu, J. M., Benhlal, J., Durand, O., et al., "Design of a lattice-matched III-V-N/Si photovoltaic tandem cell monolithically integrated on silicon substrate," Opt. Quantum Electron. 46(10), 1397-1403 (2014).

[18] Peternai, L., Jakabovič, J.., Michalka, M., "Ohmic contacts to n-and p-type GaP," 9th Int. Workshop APCOM, 157-160 (2003).

[19] Baojun, L., Enke, L.., Fujia, Z., "Pd/Zn/Pd ohmic contacts to p-type GaP," Solid-State Electron. 41(6), 917-920 (1997).

[20] Zhang, F., Zhang, D., Li, B., Liu, E., Liu, F.., Gan, R., "Pb/Zn/Pd ohmic contacts to p-GaP," Mater. Sci. Eng. B 48(3), 198-201 (1997).

[21] Montgomery, K. H., Allen, C. R., Wildeson, I. H., Jeon, J.-H., Ramdas, A. K.., Woodall, J. M., "Gettered GaP Substrates for Improved Multijunction Solar Cell Devices," J. Electron. Mater. 40(6), 1457-1460 (2011).

[22] Gershenzon, M.., Mikulyak, R. M., "RADIATIVE PAIR RECOMBINATION AND SURFACE RECOMBINATION IN GaP PHOTOLUMINESCENCE,” Appl. Phys. Lett. 8(10), 245-247 (1966).

[23] Kent, P. R. C.., Zunger, A., "Theory of electronic structure evolution in GaAsN and GaPN alloys," Phys. Rev. B 64(11), 115208 (2001).

[24] Fahy, S.., O'Reilly, E. P., "Intrinsic limits on electron mobility in dilute nitride semiconductors," Appl. Phys. Lett. 83(18), 3731-3733 (2003).

[25] Durand, O., Almosni, S., Ping Wang, Y., Cornet, C., Létoublon, A., Robert, C., Levallois, C., Pedesseau, L., Rolland, A., et al., "Monolithic Integration of Diluted-Nitride III-V-N Compounds on Silicon Substrates: Toward the III-V/Si Concentrated Photovoltaics," Energy Harvest. Syst. , 147-156 (2014).

[26] Matthews, J. W.., Blakeslee, A. E., "Defects in epitaxial multilayers: I. Misfit dislocations," J. Cryst. Growth 27, 118-125 (1974). 
[27] Grassman, T. J., Brenner, M. R., Rajagopalan, S., Unocic, R., Dehoff, R., Mills, M., Fraser, H.., Ringel, S. A., "Control and elimination of nucleation-related defects in $\mathrm{GaP} / \mathrm{Si}(001)$ heteroepitaxy," Appl. Phys. Lett. 94(23), 232106 (2009).

[28] Létoublon, A., Guo, W., Cornet, C., Boulle, A., Véron, M., Bondi, A., Durand, O., Rohel, T., Dehaese, O., et al., "X-ray study of antiphase domains and their stability in MBE grown GaP on Si," J. Cryst. Growth 323(1), 409-412 (2011).

[29] Thanh, T. N., Robert, C., Guo, W., Létoublon, A., Cornet, C., Elias, G., Ponchet, A., Rohel, T., Bertru, N., et al., "Structural and optical analyses of GaP/Si and (GaAsPN/GaPN)/GaP/Si nanolayers for integrated photonics on silicon," J. Appl. Phys. 112(5), 053521 (2012).

[30] Quinci, T., Kuyyalil, J., Thanh, T. N., Wang, Y. P., Almosni, S., Létoublon, A., Rohel, T., Tavernier, K., Chevalier, N., et al., "Defects limitation in epitaxial GaP on bistepped Si surface using UHVCVDMBE growth cluster," J. Cryst. Growth 380, 157-162 (2013).

[31] Nguyen Thanh, T., Robert, C., Létoublon, A., Cornet, C., Quinci, T., Giudicelli, E., Almosni, S., Boudet, N., Ponchet, A., et al., "Synchrotron X-ray diffraction analysis for quantitative defect evaluation in GaP/Si nanolayers," Thin Solid Films 541, 36-40 (2013). 